\title{
A burr hole button device to secure the electrode cable in depth electrode placement
}

\section{Technical note}

\section{Toshifumi Kamiryo, M.D., and Edward R. Laws Jr., M.D.}

Department of Neurological Surgery, Virginia Neurological Institute, University of Virginia, Charlottesville, Virginia

A simple magnetic resonance imaging-compatible buttonlike device was devised to fix a depth electrode cable securely in the burr hole used for its insertion during surgery for depth electrode placement. The button is tightly fixed in the burr hole and it holds the cable without allowing protrusion or tension on the wound.

Key Words * epilepsy * depth electrode * burr hole button

In cases of medically intractable seizures, depth electrode placement is an important procedure to define the focus of the seizure for possible surgical excision.[1,4,6] We previously used an orthogonal approach, $[2,9]$ but changed to an occipital burr hole approach to increase the accuracy of hippocampal recording and to lower the risk of complications. Computer software designed for three-dimensional neurosurgery planning, originally developed at the University of Virginia, has the ability to define a trajectory through the entire hippocampus.[3,5,7,8] Using this planning software, a depth electrode is placed stereotactically with a metal needle through an occipital burr hole into the amygdalohippocampus on each side. Use of this software prevents vascular injury and adapts the trajectory to the individual patient's anatomy. The occipital approach provides for better recording of the seizures and the complication rate is lower than in our experience using the orthogonal approach. It does, however, require a burr hole and a method for securing the electrode cable. Although the standard method in this situation is to fix the cable to the skin at the outlet by suturing, the skin can potentially move and thus disturb the cable. The skull bone is the most stable structure consistent with this purpose, and the authors developed a simple device that can be secured in the burr hole to hold the cable (Fig. 1). 


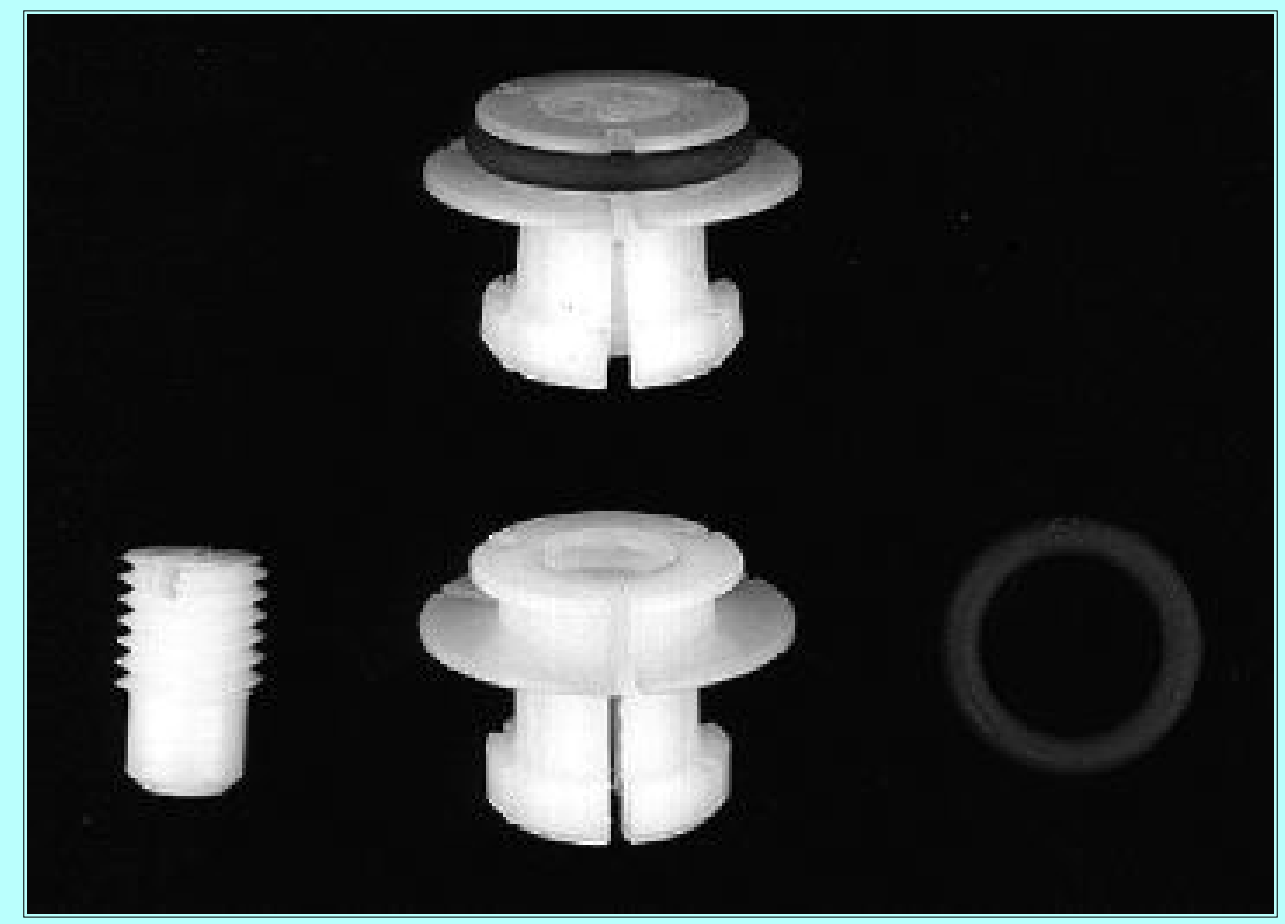

Fig. 1. Photograph of the buttonlike device. Upper: The intact device. Lower Left: Screwlike center shaft. Lower Center: The body of the device. Lower Right: Silicon ring that surrounds the body and center shaft.

\section{DESCRIPTION OF THE DEVICE}

The structure of the device is schematically shown in Fig. 2. It consists of three parts: a base, a center shaft, and a ring. The base and the center shaft are made of acetal (Delrine), and the ring is made of silicon rubber. The device is essentially a button with six split feet that are expandable by screwing in the center shaft, thereby self-securing it in the burr hole. The electrode cable goes through a split groove in the base and it is fixed at the edge of the button with the elastic ring, which prevents the cable from being pulled out. Three slits on the button can hold a maximum of three cables. The protrusion of this system from the skull is approximately $2 \mathrm{~mm}$ and it does not hinder the closure of the wound. The button is tightly fixed in the burr hole, and it cannot be pulled out without unscrewing the center shaft. This makes it suitable for potentially long duration electroencephalographic monitoring over a period of days or weeks. This device can also be sterilized easily with standard heat and pressure. 


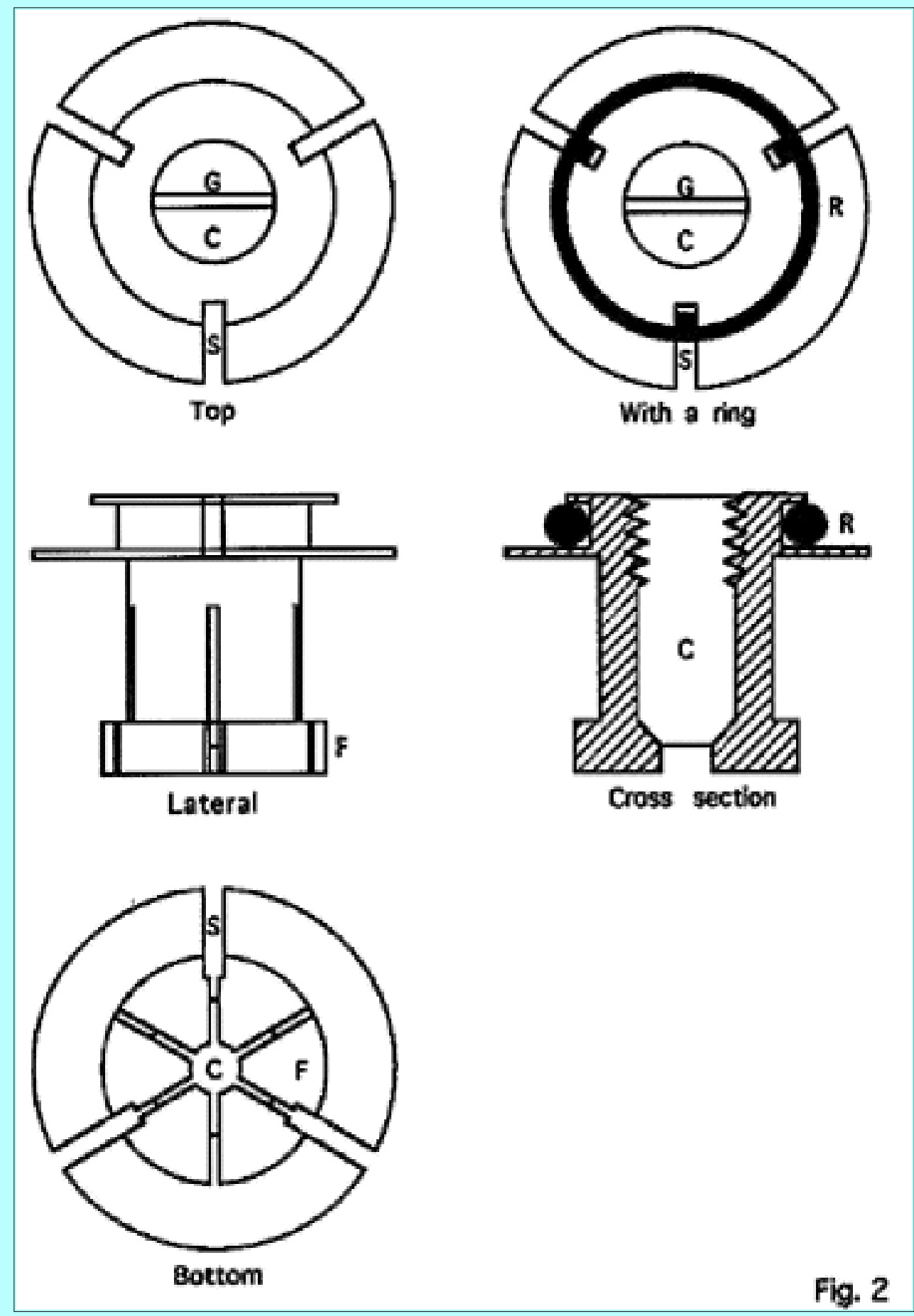

Fig. 2. Schematic drawings showing views of the buttonlike device from above (upper); lateral cross section (center); and bottom (lower). $(\mathrm{C}=$ center shaft; $\mathrm{F}=$ expandable flange; $\mathrm{G}=$ groove for a screw driver; $\mathrm{R}=$ ring for fixing the electrode cable; $\mathrm{S}=$ slit for an electrode cable).

This simple burr hole button fixes an electrode cable quickly, easily, and securely at the burr hole and aids in the safety and efficacy of epilepsy surgery.

\section{Acknowledgments}

The authors are grateful to Mr. Edwin F. Spencely, Instrument Maker Supervisor, School of Engineering and Applied Sciences, University of Virginia, for construction of the device, and Mrs. Sarah B. Hudson, 


\section{References}

1. Cohen DS, Zubay GP, Goodman RR: Seizure outcome after lesionectomy for cavernous malformations. J Neurosurg 83:237-242, 1995

2. Cosgrove GR: Lateral orthogonal approach for depth electrode insertion using the Leksell frame: technical note. Stereotact Funct Neurosurg 60:210-214, 1993

3. Goble JC, Snell JW, Hinckley K, et al: A real time system for 3D neurosurgical planning. Proc SPIE VBC 2359:552-563, 1994

4. Jooma R, Yeh HS, Privitera MD, et al: Lesionectomy versus electrophysiologically guided resection for temporal lobe tumors manifesting with complex partial seizures. J Neurosurg 83:231-236, 1995

5. Levesque MF, Wilson, CL, Behnke EJ, et al: Accuracy of MR-guided stereotactic electrode implantation. 1. Preimplantation correlation with the Talairach system. Stereotact Funct Neurosurg 58:189-193, 1992

6. Ross DA, Brunberg JA, Drury I, et al: Intracerebral depth electrode monitoring in partial epilepsy: the morbidity and efficacy of placement using magnetic resonance image-guided stereotactic surgery.

Neurosurgery 39:327-334, 1996

7. Smith JR, Hardy TL, Rose DF, et al: Comparison of CT-versus MRI-guided, computer-assisted depth electrode implantation. Stereotact Funct Neurosurg 58:189-193, 1992

8. Snell JW, Jackson TR, Katz WT, et al: Three dimensional stereotactic neurosurgical planner/stimulator. Proc SPIE Med Imaging 2431:110-118, 1995

9. Worthington C, Eastman W: Depth electrode implantation device for use with the Leksell Stereotactic frame. Stereotact Funct Neurosurg 56:129-134, 1991

Manuscript received September 17, 1996.

Accepted in final form October 16, 1996.

Address reprint requests to: Edward R. Laws Jr., M.D., Department of Neurological Surgery, Health Sciences Center, Box 212, University of Virginia, Charlottesville, Virginia 22908.

\section{Click here to view Editor's Perspective.}

